\title{
A Critical Review on effect of Optimization on Variant parameters for FACTS Device
}

\author{
Namrata Dehariya ${ }^{1}$, Vinay Pathak $^{2}$ \\ M.Tech Research Scholar, Bhopal Institute of Technology, Bhopal ${ }^{1}$ \\ Assistant Professor, Bhopal Institute of Technology, Bhopal ${ }^{2}$
}

\begin{abstract}
The demand of power system continuously increases day by day. So many problems are incurred also, like flow violation in transmission lines, voltage depression in busses, static/dynamic instabilities, voltage collapse and so on. The solution adopted by the maximum unity is the Flexible AC Transmission Systems (FACTS) devices. Most of the problem faces by us are minimized by the FACT devices but how we utilize the power of FACT devices is now a days a matter of concern. Because optimization is needed for control and efficient utilization of FACT devices. Therefore in this paper an analysis based on the previous research is being presented.
\end{abstract}

Keywords: Cluster Head Selection, Clustering, Energy Efficiency, Lifetime

\section{INTRODUCTION}

Flexible AC Transmission Systems (FACTS) devices innovation is generally thought to be a viable means for more prominent use \& better control of existing current convey limit of a power framework. It is realized that the power course through an AC transmission line is a capacity of line impedance, the size and the stage plot between the sending end and the less than desirable end voltages. By fitting coordination of UPFC (Unified Power Flow Controller), TCSC (Thyristor controlled Series Capacitor) \& SVC (Static Var Compensator) in the power framework system, both the dynamic and responsive power stream in the lines can be controlled. Tighter control of power stream and the expanded utilization of transmission limit by FACTS gadgets are talked about in [1]. A plan of power stream control in lines is examined in [2]. Utilization of static stage shifters and FACTS controllers with the end goal of expanding power move limit in the transmission line is portrayed in [3] \& [4]. In [5] creators have examined about the power stream control in transmission system. About the displaying and choice of conceivable areas for the establishment of FACTS gadgets have been examined in [6]. Appraisal and effect on power organizes by the utilization of FACTS gadgets have been examined in [7] through the idea of consistent state security areas. Designation of variable arrangement capacitor \& static stage shifters in transmission lines was the principle target in [8] for the ideal power stream. A half breed Genetic Algorithmic methodology with FACTS gadgets for ideal power stream is managed in [9]. In a congested power framework, first the areas of the FACTS gadgets were chosen focused around the affectability elements and afterward dispatch issue was illuminated in [10]. How the bound together power stream controllers can be utilized as a part of a congested power framework is examined in [11]. A GA based separate \& synchronous utilization of Thyristor Controlled Series Capacitor (TCSC), Unified Power Flow Controller (UPFC), Thyristor Controlled Voltage controller (TCVR), and
Static Var. Compensator (SVC) were considered in [12] for expanded power stream. Static VAR Compensator (SVC) is a shunt sort FACTS gadget which is utilized as a part of power framework basically with the end goal of voltage and responsive power control [13]. The improved utilization based on fuzzy controller is suggested in [14].

Section 2 shows the related work. Section 3 shows the problem domain. Section 4 discusses the analysis. The conclusions and future directions are given in Section 5. Finally references are given.

\section{RELATED WORK}

In 2012, Ahmad Rezaee Jordehi et al. [15] examines altogether about distinctive systems for arrangement of adaptable AC transmission frameworks (FACTS) enhancement issue in power frameworks. First and foremost, they clarifies the prerequisites of a perfect answer for FACTS enhancement issue, then characterizes the strategies utilized via scientists as a part of four primary gatherings as traditional systems, specialized techniques, heuristics and blended routines, and talks about altogether about attributes, points of interest and inconveniences of each one gathering of techniques. At last, a few tips are offered for future research on this region.

In 2012, Rajendraprasad Narne et al. [16] present direction control tuning of power framework stabilizer with arrangement and shunt FACTS controllers. Here thyristor controlled arrangement compensator (TCSC) and static synchronous compensator (STATCOM) based controllers are composed to upgrade the damping of power framework bury region motions. The configuration of proposed damping controller is planned as an advancement issue and the controller increases of a linearized power framework are streamlined immediately utilizing hereditary calculation (GA). Here the power framework utilized with PSS and STATCOM and TCSC. 
The facilitated tuning among the damping controllers is performed on the linearized power framework model. At long last, their proposed composed controller execution is tried with both eigen esteem investigation and time area reproductions.

In 2012, Venkata Padmavathi $S$ et al. [17] proposed that with the presentation of FACTS gadgets, the line overburdens, transport voltage issues are impressively cut down. Arrangement compensators like Thyristor Controlled Series Capacitors (TCSC) are utilized for line stream controls. The ATC can be expanded by altering the settings of the FACTS gadget, (for example, reactance, stage edges, sensitive power infusion) regarding the framework parameters. Molecule Swarm Optimization (PSO) is an evolutionary strategy that is utilized to take care of multi target advancement issue. They propose that the PSO method is utilized to gauge the possible ideal setting for the TCSC gadget to improve the power exchange ability of the framework to a considerable farthest point.

In 2012, Pateriya et al. [18] utilizes the shunt associated remuneration STATCOM based FACTS gadgets for the control of voltage and the power stream in long separation transmission line. The proposed gadget is utilized as a part of distinctive areas of transmission line furthermore manages determination of the ideal area of shunt adaptable A.c. transmission line (FACTS) gadgets for a long transmission line for voltage and power exchange change. Their results additionally demonstrate the line stacking and framework beginning working conditions.

In 2013, Ahmad Rezaee Jordehi et al. [19] propose that FACTS streamlining is a standout amongst the most imperative and troublesome issues in power frameworks. For taking care of this issue, such a large number of distinctive methodologies have been proposed prior. Among them, molecule swarm advancement (PSO) has uncovered so guaranteeing conduct. They recommend that PSO in FACTS advancement issue are clarified and investigated from the perspective of the targets, utilized essential PSO variation, PSO parameter determination, multi-target taking care of, requirement taking care of and discrete variable taking care of.

In 2013, S. A. Jumaat et al. [20] presents a methodology to sigma multi target improvement molecule swarm (6MOPSO) method for ideal portion of Flexible AC Transmission System (FACTS) gadgets. For this study, Static Var Compensator (SVC) is chosen as a recompense gadget. Proposal 6-MOPSO system has been actualized to minimize the transmission misfortunes and the expense of interest in the framework. Recreations performed on standard IEEE RTS 30-transport and IEEE 118-transport RTS. Results are contrasted and those got from the programming of multiobjective evolutionary strategy (MOEP) with a specific end goal to highlight its focal point. line impedance, terminal voltages, and voltage plot can be controlled by FACTS gadgets in a quick and compelling way [23][24]. The profit achieved by FACTS incorporates change of framework element conduct and along these lines upgrade of framework dependability. Be that as it may, their fundamental

capacity is to control power streams [25][26] . Given that they are set at ideal areas, FACTS gadgets are able to do expanding the framework loadability excessively [27]. These perspectives are assuming an inexorably noteworthy part in the operation and control of the deregulated power market [22].

Numerous investigates were made on the ideal allotment of Truths gadgets [27][28]. Nonetheless, the venture expense of FACTS also their effect on offer bends of the business sector members (suppliers and purchasers) in changed power business sector are not entirely considered [22].

Distribution of variable arrangement capacitor \& static stage shifters in transmission lines was the fundamental 
target in [29] for the ideal power stream. A cross breed Genetic Algorithmic approach with FACTS gadgets for ideal power stream is managed

in [30]. In a congested power framework, first the areas of the Certainties gadgets were chosen focused around the affectability elements and after that dispatch issue was understood in [31]. How the bound together power stream controllers can be utilized as a part of a congested power framework is examined in [32]. A GA based separate \& synchronous utilization of Thyristor Controlled Series Capacitor (TCSC), Unified Power Flow Controller (UPFC), Thyristor Controlled Voltage controller (TCVR), and Static Var Compensator (SVC) were examined in [33] for expanded power stream. But the optimality is missing [34].

\section{ANALYSIS}

Particle swarm streamlining (PSO) is a populace based stochastic improvement strategy created by Dr. Eberhart and Dr. Kennedy in 1995, roused by social conduct of feathered creature running or fish educating. PSO offers numerous similitudes with evolutionary reckoning strategies, for example, Genetic Algorithms (GA). The framework is introduced with a populace of arbitrary arrangements and scans for optima by redesigning eras. On the other hand, dissimilar to GA, PSO has no development administrators, for example, hybrid and transformation [35][36][37][38]. In PSO, the potential arrangements, called particles, fly through the issue space by taking after the current ideal particles. Every particle stays informed regarding its organizes in the issue space which are connected with the best arrangement (wellness) it has accomplished as such. (The wellness worth is additionally put away.) This quality is called pbest. An alternate "best" esteem that is followed by the molecule swarm analyzer is the best esteem, got so far by any molecule in the neighbours of the molecule. This area is called lbest. at the point when a molecule takes all the populace as its topological neighbors, the best esteem is a worldwide best and is called gbest.

In past a few years, PSO has been effectively connected in numerous research and application zones. It is showed that PSO improves brings about a speedier, less expensive route contrasted and different techniques [36][37].

An alternate reason that PSO is alluring is that there are few parameters to change. One variant, with slight varieties, functions admirably in a wide assortment of uses [36][37].

In engineering, Particle Swarm optimization (PSO) is a computational technique that improves an issue by iteratively attempting to enhance an applicant arrangement as to a given measure of value. PSO streamlines an issue by having a populace of arrangements, here named particles, and moving these particles around in the hunt space as per straightforward numerical formulae over the particles position and speed. Each particles development is impacted by its neighborhood best known position but at the same time, is guided around the best known positions in the hunt space, which are overhauled as better positions are found by different particles. This is relied upon to move the swarm around the best arrangements.

PSO is initially ascribed to Kennedy, Eberhart and Shi[38][39] and was initially expected for recreating social behaviour,[40] as an adapted representation of the development of creatures in a feathered creature run or fish school. The calculation was streamlined and it was seen to be performing advancement. The book by Kennedy and Eberhart[41] depicts numerous philosophical parts of PSO and swarm discernment. A far reaching overview of PSO applications is made by Poli.[42][43]

PSO is a metaheuristic as it makes few or no suppositions about the issue being enhanced and can look huge spaces of applicant arrangements. Be that as it may, metaheuristics, for example, PSO don't promise an ideal arrangement is ever found. All the more particularly, PSO does not utilize the angle of the issue being enhanced, which implies PSO does not oblige that the advancement issue be differentiable as is needed by exemplary enhancement techniques.

The bacterial foraging optimization (BFO) proposed by Passino in the year 2002 [44] is focused around characteristic choice that has a tendency to dispose of creatures with poor scrounging systems. After numerous eras, poor scavenging techniques are wiped out while just the people with great rummaging method survive meaning survival of the fittest. BFO forms the scrounging conduct showed by E. coli microscopic organisms as a streamlining issue. Over certain certifiable improvement issues, BFO has been accounted for to outflank a lot of people compelling streamlining calculations regarding union rate and last precision [45][46][47].

Due to the very less control parameter needed for PSO, it can be a better solution in FACTS device. After studying several research papers we find the following drawbacks:

- The Particle swarm optimization (PSO) with latency weight, No tuning for PSO parameters has been carried out and they are not satisfied.

- Overheating can be reduced and increased the lifetime.

- $\quad$ Excessive ground data can be controlled.

- Association refusal of new locales on the grounds that the site would contaminate the supply organize excessively [48][49][50][51].

Not all parameter are optimized.

The factors can be considered are as following:

a. First parameter which can be tune is the swarm size by which we can control the voltage violation.

b. Second parameter which can be tune is the weight by which we can control the voltage deviation. 
c. Third parameter which can be tune is the PSO inertia by which we can control the Transmission Line.

d. Fourth parameter which can be tune is the weight updating by which we can control the power oscillation.

e. Fourth parameter which can be tune is the velocity updating by which we can control the frequency.

\section{CONCLUSION AND FUTURE DIRECTION}

A flexible AC Transmission Systems (FACTS) device is an efficient development technology of today's era means the power system. It expands on the incredible numerous advances attained in high-present, high-control semiconductor and other engineering application, computerized control and signs picked up with the appointing and operation of high-voltage direct-current (HVDC) connections and Static VAR compensator (SVC) frameworks, over numerous decades, may have given the main thrust to looking deeper into the utilization of developing power electronic gear. Because of the, each time higher prerequisites of the risk and nature of the power the implantation of equipped for ensuring these necessities will continue expanding. So there is an extraneous need to have optimized thresholding to achieve better results. In future PSO parameters can be tuned in the controlled manner may find the better possibility in improving the efficiency. PSO is a better option because it needs very few parameters to tune and alleviate the efficiency and the performance.

\section{REFERENCES}

[1] N. Hingorani, “ Flexible AC Transmission,” IEEE Spectrum, Vol. 30, No. 4, pp. 40-45, April 1993.

[2] M. Noroozian, G. Anderson," Power Flow Control by use of controllable Series Components," IEEE Trans. Power Delivery, Vol.8, No. 3, pp. 1420-1429, July 1993.

[3] M. Iravani, P. L. Dandeno, and D. Maratukulam, "Application of Static Phase Shifters in Power Systems," IEEE Trans Power Delivery, Vol. 9, No. 3, pp. 1600-1608, July 1994.

[4] D. Ramey, R. Nelson, J. Bian, and T. Lemak, "Use of FACTS Power Flow Controllers to enhance Transmission Transfer Limits," Proceedings American Power Conference, Vol. 56, Part 1, pp. 712 718,Aril 1994.

[5] R. Nelson, J. Bian, and S. Williams, “ Transmission Series Power Flow Control," IEEE Trans. Power Delivery, Vol. 10, No. 1, pp. 504-510, Jan. 1995.

[6] D.J. Gotham and G.T.Heydt, "Power Flow Control and Power Flow Studies for System with FACTS Devices", IEEE Trans. Power System, Vol. 13, No. 1, pp. 60-65, Feb. 1998.

[7] F.D. Galiana, K. Almeida, "Assessment and Control of the Impact of FACTS Devices on Power System Performance", IEEE Transactions on Power Systems, Vol. 11, No. 4, pp. 1931-1936, Nov. 1996.

[8] T.T. Lie and W. Deng," Optimal Flexible AC Transmission Systems (FACTS) devices allocation," Int. Journal of Electrical Power \& Energy Systems, Vol. 19, No. 2, pp. 125-134, 1997.

[9] T.S. Chung and Y.Z. Li, "A Hybrid GA approach for OPF with Consideration of FACTS Devices," IEEE Power Engineering Review, pp. 54-57, Aug. 2000.

[10] S.N. Singh and A.K. David, "Optimal location of FACTS devices for congestion management", Electric Power System Research Vol. 58, pp. 71-79, 2001

[11] K.S. Verma, S.N. Singh and H.O. Gupta, "Location of Unified Power Flow Controller for Congestion Management," Electric Power Systems Research, Vol. 58, pp. 89-96, 2001.
[12] S.Gerbex, R. Cherkaoui, and A.J. Germond, "Optimal Location of Multitype FACTS Devices in a Power System by Genetic Algorithm,: IEEE Trans. Power Systems, Vol. 16, pp. 537-544, Aug. 2001.

[13] Yojna Saratkar, Arun Pachori, " Reactive Power Compensation in Transmission Line using Fuzzy Control Method: A Survey “, International Journal of Advanced Computer Research (IJACR), Volume-3, Issue-9, March-2013, pp.122-125.

[14] Yojna Saratkar, Arun Pachori, " Reactive Power Compensation on 132 KV Substation Using Soft Computing Techniques (Fuzzy Logic) " , International Journal of Advanced Computer Research (IJACR), Volume-3, Issue-9, March-2013, pp.132-139.

[15] Jordehi, A. Rezaee, and J. Jasni. "Approaches for FACTS optimization problem in power systems." In Power Engineering and Optimization Conference (PEDCO) Melaka, Malaysia, 2012 IEEE International, pp. 355-360. IEEE, 2012.

[16] Narne, R.; Panda, P.C.; Therattil, J.P., "Damping of inter-area oscillations in power system using genetic optimization based coordinated PSS with FACTS stabilizers," India Conference (INDICON), 2012 Annual IEEE, vol., no., pp.853,858, 7-9 Dec. 2012.

[17] Padmavathi, S.V.; Sahu, S.; Jayalakshmi, A., "Available transfer capability enhancement by using Particle Swarm Optimization algorithm based FACTS allocation," Microelectronics and Electronics (PrimeAsia), 2012 Asia Pacific Conference on Postgraduate Research in, vol., no., pp.184,187, 5-7 Dec. 2012.

[18] Arti Pateriya, Nitin Saxena, Manoj Tiwari, " Transfer Capability Enhancement of Transmission Line using Static Synchronous Compensator (STATCOM) " , International Journal of Advanced Computer Research (IJACR), Volume-2, Issue-7, December-2012 ,pp.83-88.

[19] Jordehi, A.R.; Jasni, J.; Wahab, N.I.A.; Kadir, M.Z.A.A., "Particle swarm optimisation applications in FACTS optimisation problem," Power Engineering and Optimization Conference (PEOCO), 2013 IEEE 7th International, vol., no., pp.193, 198, 3-4 June 2013.

[20] Jumaat, S.A.; Musirin, I.; Othman, M.M.; Mokhlis, H., "MOPSO approach for FACTS device installation in power system," Power Engineering and Optimization Conference (PEOCO), 2013 IEEE 7th International, vol., no., pp.564, 569, 3-4 June 2013.

[21] J.D. Sakala, J.S.J. Daka, "General Fault Admittance Method Solution of a Line-to-Line Fault", International Journal of Advanced Computer Research (IJACR), Volume-3, Issue-13, December-2013, pp.130-138.

[22] Cai, L. J., István Erlich, and Georgios Stamtsis. "Optimal choice and allocation of FACTS devices in deregulated electricity market using genetic algorithms." Power Systems Conference and Exposition, 2004. IEEE PES. IEEE, 2004.

[23] Galiana, F. D., K. Almeida, M. Toussaint, J. Griffin, D. Atanackovic, B. T. Ooi, and D. T. McGillis. "Assessment and control of the impact of FACTS devices on power system performance." Power Systems, IEEE Transactions on 11, no. 4 (1996): 1931-1936.

[24] Renz, B. A., A. Keri, A. S. Mehraban, C. Schauder, E. Stacey, L. Kovalsky, L. Gyugyi, and A. Edris. "AEP unified power flow controller performance." Power Delivery, IEEE Transactions on 14, no. 4 (1999): 1374-1381.

[25] Lie, Tjing T., and Wanhong Deng. "Optimal flexible AC transmission systems (FACTS) devices allocation." International Journal of Electrical Power \& Energy Systems 19, no. 2 (1997): 125-134.

[26] Chung, T. S., and Y. Z. Li. "A hybrid GA approach for OPF with consideration of FACTS devices." Power Engineering Review, IEEE 20, no. 8 (2000): 54-57.

[27] Gerbex, Stéphane, Rachid Cherkaoui, and Alain J. Germond. "Optimal location of multi-type FACTS devices in a power system by means of genetic algorithms." Power Systems, IEEE Transactions on 16, no. 3 (2001): 537-544

[28] Paterni, Pierre, Sylvain Vitet, Michel Bena, and Akihiko Yokoyama. "Optimal location of phase shifters in the French network by genetic algorithm." Power Systems, IEEE Transactions on 14, no. 1 (1999): 37-42.

[29] T.T. Lie and W. Deng," Optimal Flexible AC Transmission Systems (FACTS) devices allocation," Int. Journal of Electrical Power \& Energy Systems, Vol. 19, No. 2, pp. 125-134, 1997.

[30] T.S. Chung and Y.Z. Li, "A Hybrid GA approach for OPF with Consideration of FACTS Devices," IEEE Power Engineering Review, pp. 54-57, Aug. 2000. 
[31] S.N. Singh and A.K. David, "Optimal location of FACTS devices for congestion management", Electric Power System Research Vol. 58, pp. 71-79, 2001

[32] K.S. Verma, S.N. Singh and H.O. Gupta, "Location of Unified Power Flow Controller for Congestion Management," Electric Power Systems Research, Vol. 58, pp. 89-96, 2001.

[33] S.Gerbex, R. Cherkaoui, and A.J. Germond, "Optimal Location of Multitype FACTS Devices in a Power System by Genetic Algorithm,: IEEE Trans. Power Systems, Vol. 16, pp. 537-544, Aug. 2001.

[34] Suman Mishra, Prateek Gupta, " An efficient Optimization method for Data Classification", International Journal of Advanced Computer Research (IJACR), Volume-4, Issue-14, March-2014 ,pp.383-388.

[35] Eberhart, R. C. and Kennedy, J. A new optimizer using particle swarm theory. Proceedings of the Sixth International Symposium on Micromachine and Human Science, Nagoya, Japan. pp. 39-43, 1995.

[36] Kennedy, J. and Eberhart, R. C. Particle swarm optimization. Proceedings of IEEE International Conference on Neural Networks, Piscataway, NJ. pp. 1942-1948, 1995.

[37] Soumya I C, DeviVighneshwari, " A Novel Approach in Design of a Fuzzy Based Shunt Active Power Filter for the Enhancement of Power Quality " , International Journal of Advanced Computer Research (IJACR), Volume-4, Issue-14, March-2014 ,pp.407-413.

[38] Dubey, Ashutosh Kumar, Umesh Gupta, and Sonal Jain. "A Survey on Breast Cancer Scenario and Prediction Strategy." In Proceedings of the 3rd International Conference on Frontiers of Intelligent Computing: Theory and Applications (FICTA) 2014, pp. 367-375. Springer International Publishing, 2015.

[39] Sousa, Tiago, Arlindo Silva, and Ana Neves. "Particle swarm based data mining algorithms for classification tasks." Parallel Computing 30, no. 5 (2004): 767-783

[40] Kennedy, J.; Eberhart, R. (1995). "Proceedings of IEEE International Conference on Neural Networks" IV. pp. 1942-1948.

[41] b Shi, Y.; Eberhart, R.C. (1998). "Proceedings of IEEE International Conference on Evolutionary Computation". pp. 69-73.

[42] Kennedy, J. (1997). "Proceedings of IEEE International Conference on Evolutionary Computation". pp. 303-308.

[43] Eberhart, R.C. (2001). Swarm Intelligence. Morgan Kaufmann. ISBN 1-55860-595-9.

[44] Poli, R. (2007). "An analysis of publications on particle swarm optimization applications". Technical Report CSM-469 (Department of Computer Science, University of Essex, UK).

[45] Poli, R. (2008). "Analysis of the publications on the applications of particle swarm optimisation". Journal of Artificial Evolution and Applications 2008: 1-10.

[46] K. M. Passino, "Biomimicry of bacterial foraging for distributed optimization and control," IEEE Control Systems Magazine, vol. 22, no. 3, pp. 52-67, 2002.

[47] S. Mishra, "A hybrid least square-fuzzy bacterial foraging strategy for harmonic estimation," IEEE Transactions on Evolutionary Computation, vol. 9, no. 1, pp. 61-73, 2005.

[48] S. Mishra and C. N. Bhende, "Bacterial foraging technique-based optimized active power filter for load compensation," IEEE Transactions on Power Delivery, vol. 22, no. 1, pp. 457-465, 2007.

[49] Naresh Kumari, A. N. Jha, "Frequency Response Enhancement of Hybrid Power System by using PI Controller Tuned with PSO technique", International Journal of Advanced Computer Research (IJACR), Volume-4, Issue-14, March-2014, pp.116-122.

[50] Animesh Dubey, Rajendra Patel and Khyati Choure, " An Efficient Data Mining and Ant Colony Optimization technique (DMACO) for Heart Disease Prediction " , International Journal of Advanced Technology and Engineering Exploration (IJATEE), Volume-1, Issue-1, December-2014,pp.1-6.

[51] A. Biswas, S. Dasgupta, S. Das, and A. Abraham, "A synergy of differential evolution and bacterial foraging optimization for faster global search," International Journal on Neural and Mass-Parallel Computing and Information Systems, pp. 607-626, 2007. 